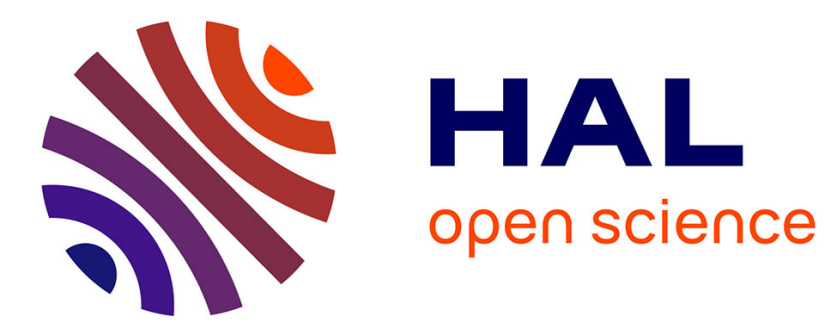

\title{
Magnetooptics in Charge Uncompensated Garnet CaxY3-xFe5O12
}

\author{
M. Kucera, P. Beránková, M. Matyás, M. Marysko, K. Nitsch
}

\section{To cite this version:}

M. Kucera, P. Beránková, M. Matyás, M. Marysko, K. Nitsch. Magnetooptics in Charge Uncompensated Garnet CaxY3-xFe5O12. Journal de Physique IV Proceedings, 1997, 07 (C1), pp.C1-709-C1-710. 10.1051/jp4:19971288 . jpa-00255001

\section{HAL Id: jpa-00255001 https://hal.science/jpa-00255001}

Submitted on 1 Jan 1997

HAL is a multi-disciplinary open access archive for the deposit and dissemination of scientific research documents, whether they are published or not. The documents may come from teaching and research institutions in France or abroad, or from public or private research centers.
L'archive ouverte pluridisciplinaire HAL, est destinée au dépôt et à la diffusion de documents scientifiques de niveau recherche, publiés ou non, émanant des établissements d'enseignement et de recherche français ou étrangers, des laboratoires publics ou privés. 


\title{
Magnetooptics in Charge Uncompensated Garnet $\mathrm{Ca}_{x} \mathrm{Y}_{3-x} \mathrm{Fe}_{5} \mathrm{O}_{12}$
}

\author{
M. Kucera, P. Beránková, M. Matyás, Jr., M. Marysko* and K. Nitsch* \\ Institute of Physics, Charles University, Ke Karlovu 5, 12116 Prague 2, Czech Republic \\ * Institute of Physics, AS CR, Cukrovarnická 10, 16200 Prague 6, Czech Republic
}

\begin{abstract}
The properties of compensating centres in $\mathrm{Ca}^{2+}$ substituted yttrium iron garnet $\mathrm{Ca}_{\mathrm{x}} \mathrm{Y}_{3-\mathrm{x}} \mathrm{Fe}_{5} \mathrm{O}_{12}, 0 \leq \mathrm{x} \leq 0.39$, have been investigated using magnetooptical spectroscopy and magnetization measurements. The Faraday rotation and MCD were measured in the spectral range from 0.5 to $2.5 \mathrm{eV}$ and at temperatures from 6 to $380 \mathrm{~K}$. Different centres were detected and the effects of their localization at low temperatures are discussed.
\end{abstract}

The Faraday rotation (FR) and magnetic circular dichroism (MCD) provide a sensitive tool for investigation of properties of compensating centres in iron garnets doped with divalent $\mathrm{Ca}^{2+}$ ions. In particular, two distinct types of centres were resolved in Ca:YIG which differ in spectral behaviour of the magnetooptical (MO) effects [1]. In this paper we present the first results of MO studies of highly doped and partly compensated Ca:YIG at liquid helium temperatures. We concentrate here on the properties of 'type II' centres, the results on 'type I' centres were published elsewhere [2].

A series of liquid phase epitaxial films $\mathrm{Ca}_{x} \mathrm{Y}_{3-\mathrm{x}} \mathrm{Fe}_{5} \mathrm{O}_{12}, 0 \leq \mathrm{x} \leq 0.39$, were isothermally grown from $\mathrm{PbO}-\mathrm{B}_{2} \mathrm{O}_{3}$ flux on (111) and (001) oriented GGG substrates at temperatures between 880 and $960^{\circ} \mathrm{C}$. The composition of samples was determined by electron probe microanalysis and their thickness by spectroscopic interferometry. The FR and MCD were measured in the spectral range from 0.5 to $2.2 \mu \mathrm{m}(0.55$ to $2.5 \mathrm{eV})$ and at temperatures from 6 to $380 \mathrm{~K}$. The magnetization measurements were performed on the SQUID magnetometer in the temperature range from 3 to $300 \mathrm{~K}$. The basic properties of samples here reported are summarized in the Table 1.

The $\mathrm{Ca}^{2+}$ doping induces broad spectral bands in the near infrared and visible ranges of both the MCD and FR spectra, Fig.1. The shape of this induced structure is dependent on the type of compensating centre involved. In particular, type I centres induce absorption-like bands in the MCD spectrum with maxima near 0.78 and $1.39 \mathrm{eV}$ and with zero-crossing points at 1.08 and $1.5 \mathrm{eV}$ [2]. On the contrary, type II centres induce bands of different shape with maxima near $1.2 \mathrm{and} 1.6 \mathrm{eV}$ and being zero at 1.4 and below $0.8 \mathrm{eV}$, cf. [1]. This unique property makes possible to determine unambiguously the presence of individual types of centres and to determine their relative concentration simply by measuring the MCD at a suitable wavelength. Similar considerations based on the FR spectra are not so straight-lined in view of dispersion nature of the latter effect. In this respect the spectra in Fig. 1 sustain that the as-grown V7 sample contains only type II centres whereas in the sample V4 both types of centres are present; the sample C6 contains only type I centres [2].

While the FR of pure YIG originating from $d$-states of $\mathrm{Fe}^{3+}$ ions is almost temperature independent in the region from liquid helium to room temperatures, the intensity of Ca-induced components in the MO spectra considerably raises with decreasing temperature. The temperature dependencies of the MCD and FR are displayed in the Fig. 2. The wavelengths were chosen in such a way that the MCD curves reflect the contribution related only to one type of respective centres (either type I for C6 or type II for V4 and V7) without interference with contribution from iron $\mathrm{Fe}^{3+}$ ions. This consideration is not valid for the temperature dependence of the FR of sample V4 displayed also in the Fig. 2, where the competing contributions originating from octa- and tetrahedral $\mathrm{Fe}^{3+}$ ions dominate and as a result a broad maximum is observed around $200 \mathrm{~K}$. The temperature dependencies of the MCD have very similar form

Table 1. Basic properties of $\mathrm{Y}_{3-\mathrm{x}-\mathrm{y}} \mathrm{Ca}_{\mathrm{x}} \mathrm{Pb}_{\mathrm{y}} \mathrm{Fe}_{5-\mathrm{z}} \mathrm{Pt}_{\mathrm{z}} \mathrm{O}_{12}$ samples, $\mathrm{t}$ - film thickness, $\mathrm{T}_{\mathrm{G}}$ - growth temperature.

\begin{tabular}{llrrrll}
\hline Sample & \multicolumn{1}{c}{$\mathrm{x}$} & $\mathrm{y}$ & \multicolumn{1}{c}{$\mathrm{z}$} & $\mathrm{t}[\mu \mathrm{m}]$ & $\mathrm{T}_{\mathrm{G}}\left[{ }^{\circ} \mathrm{C}\right]$ & centres \\
\hline V4 (001) & 0.148 & 0.028 & $<0.03$ & 4.56 & 880 & $\mathrm{I}, \mathrm{II}$ \\
V7 (111) & 0.39 & 0.025 & $<0.03$ & 2.85 & 960 & II \\
C6 (111) & 0.22 & 0.01 & 0.01 & 4.05 & 910 & $\mathrm{I}$ \\
\hline
\end{tabular}
in all samples, Fig. 2. The MCD first increases nearly linearly with decreasing temperature and below $40 \mathrm{~K}$ it is almost temperature independent. A slight reduction of MCD value $(\leq 1.5 \%)$ towards liquid helium temperatures is inconclusive being close to the experimental error. However, the low temperature decrease in magnetization is evident, Fig.2. It should be mentioned that between 300 and 


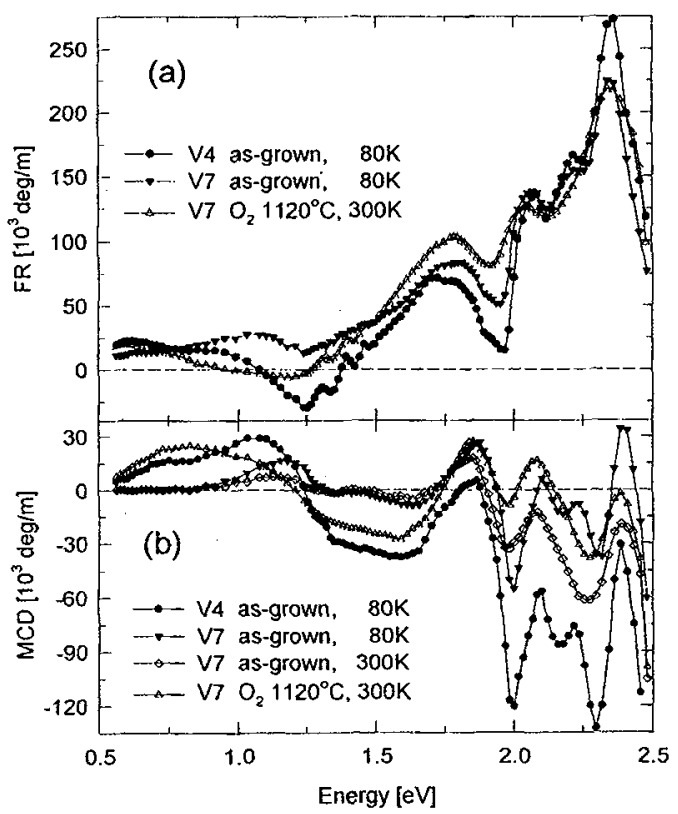

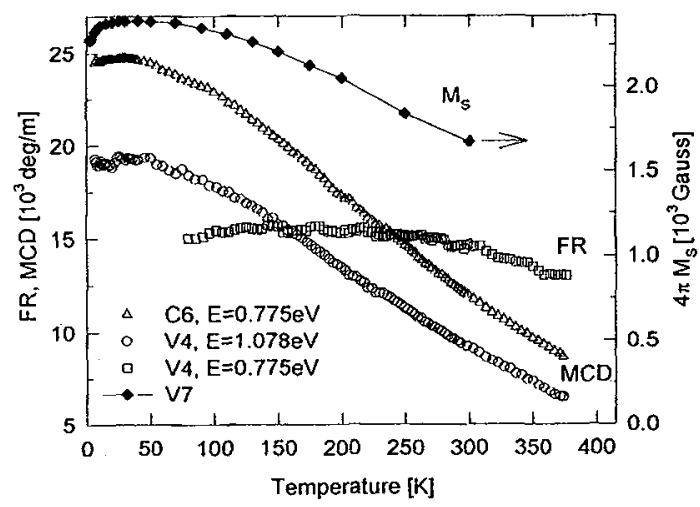

Figure 1 (left): The Faraday rotation (a) and $\mathrm{MCD}$ (b) spectra at $\mathrm{T}=$ 80 and $300 \mathrm{~K}$ for as-grown and annealed samples.

Figure 2 (above): The temperature dependencies of the MCD and Faraday rotation at different wavelengths, and magnetization curve for smaple V7. The MCD value for sample C6 should by multiplied by a factor of 2.5 .

$20 \mathrm{~K}$ the value of the MCD increases 2.1 times while the magnetic moment increases in this range only by a factor of 1.45 .

The population of different centres can be easily altered by a proper heat treatment in oxidizing or reducing atmosphere. The annealing in oxygen $\left(1120^{\circ} \mathrm{C} / 6\right.$ hours) creates type I centres and causes an adequate gain of intensities of $\mathrm{MO}$ phenomena $[1,2]$. The effect is demonstrated for V7 sample, where two new bands are induced in the near ir range, Fig. 1b. This process is reversible and thermal annealing in reducing $\mathrm{H}_{2}$ atmosphere $\left(250-350^{\circ} \mathrm{C}\right)$ causes the fall of concentration of centres towards zero due to the generation of oxygen defects. The spectra of the FR and MCD in samples annealed in $\mathrm{H}_{2}$ are close to those of a pure YIG [2]. The annealing experiments are thoroughly described in [1].

In spite of entirely different $\mathrm{MO}$ properties of $\mathrm{Ca}$ YIG depending on type of a centre present, the magnetization measurements did not show any obvious correlation between magnetic moment on the one hand and concentration and type of compensating centres on the other hand. Even the change of concentration of type I centres in sample C6 from zero to maximum after the heat treatment did not influence significantly the magnetic moment and the shape of magnetization curve at low temperatures. We observed a slightly higher magnetic moment (of the order of $1 \%$ ) in $\mathrm{O}_{2}$ annealed samples compared to $\mathrm{H}_{2}$ annealed ones. In most samples we observed a weak reduction of a magnetic moment at liquid helium temperatures of the order $2-5 \%$ (compared to the value at $20 \mathrm{~K}$ ) independent on the type of the centre involved. This decrease is currently explained by the localization of an electron hole at iron ion [3] or at oxygen anion [4] at low temperatures creating thus paramagnetic $\mathrm{Fe}^{4+}$ or $\mathrm{O}^{1-}$ ions coupled by superexchange interaction to the $\mathrm{Fe}^{3+}$ cations. However, the temperature dependence of the $\mathrm{MCD}$, which reflects only the behaviour of compensation centres without contribution from $\mathrm{Fe}^{3+}$ ions, does not reveal any sharp localization effects expected for large polaron [3].

In conclusion, the magnetooptic and magnetic measurements on $\mathrm{Ca}^{2+}$ doped YIG containing both type I and II compensating centres do not provide evidence for localization of holes on either iron or oxygen atoms at low temperatures. Likewise the MO spectra measured at $10 \mathrm{~K}$ (not reported here) did not reveal any new structure compared to 80 or $300 \mathrm{~K}$ spectra which would indicate the effects of localization, as well. The mesurements of the quadratic MO effects indicate rather uniform distribution of the compensating centres over the magnetic sublattices.

\section{Acknowledgements}

The authors thanks to V.V.Volkov and M.Nevřiva for providing some samples and J.Šimšová for composition analysis. This work has been supported by the grant GAUK-9.

\section{References}

[1] Milani E. and Paroli P., J.Magn.Mag.Mat. 72 (1988) 209-214.

[2] M.Kučera, P.Beránková, K.Nitsch, and M.Matyáš, J.Magn.Mag.Mat. 158 (1996)

[3] Pardavi-Horvath M., Thavendrarajah A., Wigen P.E., J.Magn.Mag.Mat. 119 (1993) 193-204.

[4] Maryško M., Novák P., Púst L., et al., J.Physique Coll. 49 C8 (1988) 981-2. 